\title{
Detection of adeno-associated virus type 2 genome in cervical carcinoma
}

\author{
BY Zheng*, ${ }^{*, 6}$, XD Li ${ }^{1,6}$, F Wiklund ${ }^{2}$, S Chowdhry', T Ångstrom ${ }^{3}$, G Hallmans ${ }^{4}$, J Dillner ${ }^{5}$ and KL Wallin' \\ 'Department of Molecular Medicine and Surgery, Karolinska Institute, Center for Molecular Medicine, Karolinska University Hospital Solna, Stockholm \\ 171 76, Sweden; ${ }^{2}$ Oncology Center, Umeå University Hospital, Umeå, Sweden; ${ }^{3}$ Cytology Laboratory, Umeå University Hospital, Umeå, Sweden; \\ ${ }^{4}$ Department of Public Health and Clinical Medicine, Nutritional Research, Umeå University Hospital, Umeå, Sweden; ${ }^{5}$ Department of Medical \\ Microbiology, Lund University, Malmö University Hospital, Malmö, Sweden
}

Adeno-associated virus (AAV) can impair the replication of other viruses. Adeno-associated virus seroprevalences have been reported to be lower among women with cervical cancer. In-vitro, AAV can interfere with the production of human papillomavirus virions. Adeno-associated virus-2 DNA has also been detected in cervical cancer tissue, although not consistently. To evaluate the role of AAV infection in relation to invasive cervical cancer, we performed a nested case-control study within a retrospectively followed population-based cohort. A total of 104 women who developed invasive cervical cancer on average 5.6 years of follow-up (range: 0.5 months-26.2 years) and 104 matched control-women who did not develop cervical cancer during the same follow-up time were tested for AAV and human papillomavirus by polymerase chain reaction. At baseline, two (2\%) case-women and three (3\%) control-women were positive for AAV-2 DNA. At the time of cancer diagnosis, 12 (I2\%) case-women and 3 (3\%) matched control-women were positive for AAV-2 DNA. Persisting AAV infection was not evident. In conclusion, AAV-2 DNA was present in a low proportion of cervical cancers and we found no evidence that the presence of AAV in cervical smears of healthy women would be associated with reduced risk of cervical cancer.

British Journal of Cancer (2006) 94, 1913-1917. doi:10.1038/sj.bjc.6603179 www.bjcancer.com

Published online 30 May 2006

(c) 2006 Cancer Research UK

Keywords: adeno-associated virus; AAV; cervical cancer; human papillomavirus; HPV

Cervical cancer ranks as the second most common cancer among women worldwide. Human papillomavirus (HPV) infection has been established as the main causal factor for cervical cancer (Munoz et al, 2003; Schiffman and Castle, 2003). During carcinogenesis, integration of high-risk HPV causes imbalance in the expression of the viral oncoproteins E6 and E7 which degrades tumour suppressor genes p53 and retinoblastoma protein (Rb), respectively (Alazawi et al, 2002). Proposed cofactors to HPV in cervical carcinogenesis include other sexually transmitted infections such as Chlamydia trachomatis infection (Koskela et al, 2000), smoking and genetic risk factors (Ghaderi et al, 2002), but these have not fully explained why some HPV-exposed women develop cancer and others do not.

Adeno-associated virus is a helper-dependent parvovirus that needs co-infection with other viruses, such as adenovirus (Atchison et al, 1965; Henry, 1973), HPV (Hermonat, 1994; Su and $\mathrm{Wu}, 1996$; Hermonat et al, 1997), vaccinia virus (Schlehofer et al, 1986) or herpes simplex virus (HSV) (Salo and Mayor, 1979; Buller et al, 1981) to help its replication. Among all AAV types, AAV-2 is the common cause of infection in humans (FriedmanEinat et al, 1997). Adeno-associated virus-2 Rep78 gene inhibits HPV-induced cell transformation in vitro (Hermonat, 1994; Hermonat et al, 1997; Zhan et al, 1999), thus suggesting the

\footnotetext{
*Correspondence: Dr BY Zheng; E-mail: biying.zheng@cmm.ki.se

${ }^{6}$ These authors share the first authorship.

Received 28 November 2005; revised 12 April 2006; accepted 25 April 2006; published online 30 May 2006
}

inhibition of HPV gene expression by AAV-2. However, Ahn et al (2006) could not show any significant viral inhibition in all cervical cancer cell lines by the AAV-2 Rep 78 gene.

An inverse association between seropositivity for AAV-2 and cervical cancer has been reported (Mayor et al, 1976; Georg-Fries et al, 1984). However, studies on detection of AAV DNA in cervical smears or biopsies do not fully support the serological findings. Several studies detected AAV DNA in cervical samples (Han et al, 1996; Venturoli et al, 2001; Ahn et al, 2003), while others failed to detect AAV DNA in cervical samples (Strickler et al, 1999; Odunsi et al, 2000). Coker et al (2001) found that AAV is associated with reduced risk in high-grade squamous intra epithelial lesion (HSIL), but not low-grade squamous intraepithelial lesion (LSIL). However, Ahn et al (2003) found that AAV is not associated with all stages of cervical precancer and invasive cancer lesions by in situ hybridisation and immunohistochemistry.

Whether presence of AAV DNA is associated with cervical cancer risk has not been assessed in an epidemiological controlled format. The aim of this study was to investigate if AAV-2 infection was associated with decreased or increased risk for future development of cervical cancer, using a retrospective, populationbased study design.

\section{MATERIALS AND METHODS}

\section{Study base}

The study base consisted of the women residing in the Västerbotten county in northern Sweden who attended the population- 
based four-yearly interval invitational cervical screening programme. The population in the county was 260472 inhabitants of whom 130651 were women in 1995. The programme invites women in the age group of 25-59 years to participate and it has an attendance rate of $>80 \%$ since it was introduced in 1969. All cervical cancer patients are treated at the Umea University Hospital and all clinical data are stored in the same hospital. Similarly, all cytological diagnoses are made and all specimens stored at the Cytology Laboratory, Umeå University Hospital (Wallin et al, 1999).

\section{Study design}

The study was based on an earlier case - control retrospective study as described in Wallin et al (1999). Eligible case-women had been diagnosed with invasive cancer between the years 1969-1995 after having had at least one normal smear taken, had at least one additional smear (irregardless of its cytological diagnosis) taken and had not had any operative treatment of the cervix. A total of 133 eligible case-women were identified by linking the cytological registry with the Swedish National Cancer Registry. Further linkage to the pathological registry was made for the retrieval of histopathological samples for re-review and laboratory analysis. Four women were excluded due to incorrect entries into the cancer registry, 12 due to missing histopathological specimens and 11 due to non-invasive cervical neoplasia, leaving 106 cases of invasive cervical cancer. Of these two biopsies were inadequate for polymerase chain reacion (PCR) analysis, leaving 104 cases (85 squamous cell carcinoma and 19 adenocarcinoma), with serial samples available for the study. Control subjects were women from the same study base who did not develop cervical cancer during the same period before the diagnosis of cancer in their corresponding cases. Each control was matched one to one to its case according to age and time of sampling of the baseline smears and existence of normal follow-up smears matched in time of sampling to the cervical cancer biopsies. Thus, each case-woman contributed a normal smear taken before invasive cancer diagnosis and a histological sample with a confirmed diagnosis of cervical carcinoma, and each control woman contributed two normal smears matched to the normal smear and biopsy of its corresponding case. The mean time between the sampling of the baseline smear and cancer diagnosis was 5.6 years (range: 0.5 months -26.6 years). The average age at which the baseline smear was obtained was 44 years (range: 19-74) among the women with cancer and 44 years (range: 20-74) among the control-women. The dates of the smears of the women with cancer and those of the control-women differed by 1 month, on average. The subsequent smears of the control-women were typically obtained after the diagnosis of cancer in the corresponding women with cancer, as absence of disease in the controls for at least the same duration of follow-up was an essential component of the study design. If a control-woman had several normal smears after the date of the diagnosis of cancer in the corresponding woman with cancer, the smear obtained on the date closest to the date of the diagnosis of cancer was chosen. The time of biopsy in the woman with cancer and the time the smear was obtained in the corresponding control-woman differed by up to 10 months. The average age of the women with cancer at the time of diagnosis was 50 years (range: 24-79), and the average age of the control-women at the time of the second normal smear was 50 years (range: 24-79) (Wallin et al, 1999).

All cytological smears and histological slides were re-evaluated before laboratory analysis. Ethical approval was obtained from the Institutional Review Board of Umea University. As decided by the Institutional Review (IRB): Umeå University (2003-02-11, 98/03, Dnr 98-12), information about the study was made known to the public that donated the samples by press conferences.

\section{DNA extraction from paraffin sections and archival Pap smears}

DNA was extracted from archival smears and biopsies as described earlier (Chua et al, 1996). In brief, coverslips of Pap smears were removed with xylene and the cytoplasmic stain was removed in $95 \%$ ethanol. A mild lysis buffer containing $25 \mu$ l of proteinase $\mathrm{K}$ $\left(20 \mathrm{mg} \mathrm{ml}^{-1}\right.$ ) (Sigma, Sigma-Aldrich, Hamburg, Germany) per $1.0 \mathrm{ml}$ of buffer was used to dislodge the cells off the glass slide, and the cells were pipetted into a sterile Eppendorf tube. An additional $10 \mu \mathrm{l}$ of proteinase $\mathrm{K}$ was added and digestion was carried out at $55-60^{\circ} \mathrm{C}$ for a minimum of $2 \mathrm{~h}$. Protein was precipitated by the addition of $100 \mu \mathrm{l}$ saturated ammonium acetate, and centrifuged at $14000 \mathrm{rpm}$ at room temperature for $5 \mathrm{~min}$. DNA was precipitated using cold ethanol and dissolved in low EDTA, tris-EDTA (TE) buffer.

Four $5 \mu \mathrm{m}$-thick sections were taken from each paraffin block. Knives were changed and an empty paraffin block sectioned in between each biopsy to prevent cross-contamination. The fifth section was stained with haematoxylin and eosin for review to ensure that the proceeding sections contained tumour tissue for PCR analysis. Deparaffinization was carried out in xylene and the tissue rehydrated through graded alcohols, then air-dried and digested with buffer containing $10 \mu \mathrm{l}$ proteinase $\mathrm{K}\left(20 \mathrm{mg} \mathrm{ml}^{-1}\right)$. Digestion was carried out at $60^{\circ} \mathrm{C}$ for a minimum of $2 \mathrm{~h}$ until a clear lysate was obtained. Heating the samples at $98^{\circ} \mathrm{C}$ for $10 \mathrm{~min}$ inactivated proteinase $\mathrm{K}$.

All samples were tested for DNA integrity by PCR using human ribosomal gene S14 primers, which gave $150 \mathrm{bp}$ amplimers. The blank sections were tested by S14 PCR to check for contamination during sectioning.

\section{Adeno-associated virus polymerase chain reaction}

As positive control, DNA extracted from HA-16 cells (kindly donated by Professor JR Schlehofer) was used. It is a cervical cancer cell line HeLa (containing HPV 18) transfected with AAV-2 (Walz and Schlehofer, 1992). These cells were grown in DMEM medium (PAA laboratories $\mathrm{GmbH}$, Austria) supplemented with $10 \%$ fetal calf serum (FCS), streptomycin $\left(50 \mathrm{mg} \mathrm{ml}^{-1}\right)$ and penicillin $\left(500 \mathrm{U} \mathrm{ml}^{-1}\right)$ and DNA was extracted for PCR. DNA was extracted according to the standard protocols and measurements were made by UV-1601spectrophotometer (Shimadzu, Japan).

Three primer pair sets were chosen for AAV detection. (1) The pan 1/pan 3 primer pairs are general primers for AAV-2, -3 and -5 which have a size of $338 \mathrm{bp}$ (Tobiasch et al, 1998). A sensitive panel was set up for pan AAV PCR, in which total HA-16 DNA concentration varied at 50,100,250 and $500 \mathrm{pg}$. Negative controls for AAV consisted of DNA extraction from HeLa cell line, and blanks containing no DNA were also included. The detection limit for the pan-AAV primers PCR system was $100 \mathrm{pg}$ total HA-16 DNA. (2) Non-nested AAV-2 primers (Han et al, 1996) and (3) AAV-nested PCR (Mehrle et al, 2004), both AAV-2 PCR systems, target the AAV-2 rep gene. They were tested against a sensitive panel total HA-16 DNA with DNA concentration ranging from $230 \mathrm{ng}$ to $0,23 \mathrm{pg}$. The detection limit for non-nested AAV-2 PCR system was $23 \mathrm{pg}$ while that of nested AAV-2 was 2, $3 \mathrm{pg}$. Oligonucleotide primers used in this study are detailed in Table 1.

Optimisation of the PCR reactions was tested at different annealing temperatures, primer concentrations and $\mathrm{MgCl}_{2}$ concentrations. DNA amplification was performed in a $50 \mu \mathrm{l}$ reaction mix containing 1.0-3.0 $\mu$ l of template DNA, and for second round nested PCR, $5 \mu \mathrm{l}$ of the first round of PCR product was used as template DNA, $1 \times$ PCR buffer, 1.5-2.0 $\mathrm{mM} \mathrm{MgCl}_{2}, 0.2 \mathrm{mM}$ of each of dATP, dCTP, dTTP, dGTP (Roche, Germany), 10 pmol of each of pan-AAV or AAV-2 primers, respectively, $5 \mu \mathrm{l}$ of $2 \%$ BSA and $1.0-$ 1.5 U Taq DNA polymerase (Promega, Madison WI, USA). 
Table I Oligonucleotide primers used in this study

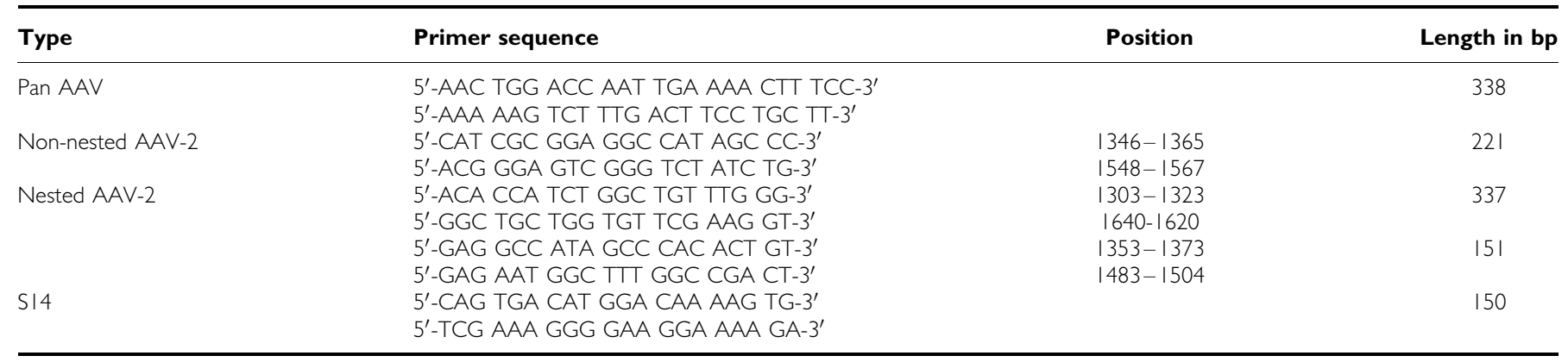

Polymerase chain reactions were performed using Peltier Thermol Cyclerb PTC-100 (MJ Research, Inc. Waltham, MA, USA). The PCR reaction consisted of 40 cycles with the denaturation step at $94^{\circ} \mathrm{C}$ for $30 \mathrm{~s}$, followed by the annealing step at $62^{\circ} \mathrm{C}$ for pan-AAV or $64^{\circ} \mathrm{C}$ for non-nested AAV-2 or $62^{\circ} \mathrm{C}$ for nested AAV-2 PCR, respectively, for $30 \mathrm{~s}$ and extension at $72^{\circ} \mathrm{C}$ for $45 \mathrm{~s}$. Each PCR was initiated by one denaturation step at $95^{\circ} \mathrm{C}$ for $1 \mathrm{~min}$ before the amplification cycles and completed by one extension step at $72^{\circ} \mathrm{C}$ for $5 \mathrm{~min}$ after 40 amplification cycles. A volume of $10 \mu \mathrm{l} \mathrm{PCR}$ products were loaded into $2 \%$ agarose gel and visualised with ethidium bromide. Positive PCR products were sequenced according to the protocol for ABI Prism ${ }^{\mathrm{TM}}$ BigDye $^{\mathrm{TM}}$ Terminator Cycle Sequencing Ready Reaction Big Dye Terminators Kit kit (Perkim Elmer Applied Biosystems, Foster City, CA, USA). Blanks containing no DNA were included as contamination controls. Varying amounts of template DNA was used on repeated PCR runs to overcome the effect of inhibitors present in the DNA extraction.

To test the specificity of the AAV PCR systems, different PCR primer sets directed towards pan-AAV, AAV-2 (nested or nonnested) and HPV amplification were tested on DNA from HA-16 cells (contain HPV 18 and AAV-2), SiHa cells (contain HPV 16) and HeLa cells (contain HPV18).

\section{Human papillomavirus polymerase chain reaction}

The HPV consensus primers MY09/MY11 and GP5+/6+ were used in single-tube nested PCR, where the GP5 $+/ 6+$ products were amplified in abundance for gel electrophoresis and HPV typing by DNA sequencing. Details of the procedure had been published (Wallin et al, 1999). The PCR analyses were performed blind to cases or controls and were analysed at the same time, to avoid the risk of assay performance variation. The sensitivity of the PCR system was based on dilutions of HPV-16 L1 plasmids (1 copy to 500 copies) mixed with $2 \mu \mathrm{l}$ of DNA extracts from 10 HPV PCRnegative cervical smears as a check for PCR inhibition. Dilutions of (1 fg-10 pg) DNA extracts from HPV-16-positive SiHa cervical cancer cell-line were also included into each PCR run as a sensitivity panel. DNA from HPV-16-positive CaSki and HPVnegative C33A cervical cancer cell-lines were also included as controls (Wallin et al, 1999).

\section{HPV DNA typing}

Human papillomavirus typing was performed first with typespecific primers for HPV-16 (E1: 1768-1960) and HPV-18 (E7: $591-900)$ as described (Evander et al, 1991). Samples that were HPV-positive by general primers but negative by type-specific primers were subjected to DNA sequencing of the GP5 $+16+$ amplimers according to the ABI Prism ${ }^{\mathrm{TM}}$ BigDye $^{\mathrm{TM}}$ Terminator Cycle Sequencing Ready Reaction Big Dye Terminators Kit (PE Applied Biosystems, Perkim-Elmer Corp., Foster City, CA, USA) and sequenced using the ABI 310 sequencer (PE Applied Biosystems).

\section{Statistical analysis}

Relative risk with $95 \%$ confidence interval (CI) was estimated as odds ratio (OR) by logistic regression using epiinfo software (Epi Info 2000, Centers for Disease Control and Prevention, Atlanta, Georgia, USA).

\section{RESULTS}

The PCR primer specificity test showed a positive band using the pan-AAV and the two AAV-2 PCR systems with HA-16 DNA but not when $\mathrm{SiHa}$ or HeLa cell DNA was used as template. HPV general primers gave a positive band when all three cervical cancer cell-lines were tested, which is expected as they all contain HPV DNA.

The level of sensitivity for the three PCR systems used in this study was $2.3 \mathrm{pg}$ HA-16 DNA for nested AAV-2, 23 pg for nonnested AAV-2 and $100 \mathrm{pg}$ for pan-AAV. The detection limits were repeatable and consistent in each PCR run for each system. The S14 PCR, which was incorporated to test the amplifiability of DNA, was positive in all samples tested in this material. To overcome possible intrinsic inhibition of PCR amplifications, three different rounds of PCR of the entire study material were repeated using $1-3 \mu \mathrm{l}$ of template DNA.

For pan-AAV PCR, AAV DNA was not detectable in any of the baseline smears and their corresponding matched controls, nor in the cervical cancer biopsies. The non-nested AAV-2 PCR system detected AAV DNA in one cervical cancer biopsy and one control smear matched to a cancer biopsy. With the nested AAV-2 PCR, $2 / 104(2 \%)$ of the prediagnostic smears of cancer cases and 3/104 (3\%) of the prediagnostic smears of matched control-women were positive for AAV DNA. At cancer diagnosis, 12/104 (11.7\%) of biopsies with cancer were positive and 3/104 (3\%) of matched control smears to the biopsies were positive for AAV DNA (OR for cancer in case of AAV DNA positivity: 4.39 (95\% CI: $1.11-20.29$ ). Persisting AAV infection in the same woman was not found in any one of the women in our study (Table 2). Results of the HPV DNA testing have been reported previously (Wallin et al, 1999). In brief, HPV DNA status at baseline among cytologically normal smears for cases was $29.8 \%(31 / 104)$ as compared to $2.8 \%$ (3/104) among controls. Seventy-seven percent $(80 / 104)$ had HPV DNA in the cervical cancer biopsies. Of these case-women, 27 had persistent HPV DNA at both the baseline smear and the cancer biopsy, while only one control-woman was HPV DNA-positive in her baseline smear and her second smear, thus conferring an increased risk of 58.7 (95\% CI: $10.2-\infty)$ (Wallin et al, 1999).

When we compared the presence of AAV-2 DNA with HPV DNA of the same sample in the entire study material, none of the 
Table 2 AAV-2 prevalence among 104 cervical cancer biopsy specimens and 104 matched control cytological normal Pap smears by nested AAV-2 PCR

\begin{tabular}{lcc}
\hline & Prediagnostic smears $^{\mathbf{a}}$ & Cancer biopsies/Matched smears \\
\hline Cases & $2^{\mathrm{a}}$ & $12^{\mathrm{a}}$ \\
Controls & $3^{\mathrm{a}}$ & $3^{\mathrm{a}}$ \\
\hline
\end{tabular}

a None of them represent the same patient.

Table 3 Comparison of the presence of AAV-2 DNA with HPV DNA in 104 cervical cancer biopsy specimens and 104 matched control smears

\begin{tabular}{lcccc}
\hline & HPV+ & HPV+ & HPV - & HPV - \\
& AAV+ & AAV - & AAV+ & AAV- \\
\hline Invasive cancer biopsies & $10(10 \%)$ & $70(67 \%)$ & $2(2 \%)$ & $22(21 \%)$ \\
Match control smears & $0(0 \%)$ & $4(4 \%)$ & $3(3 \%)$ & $97(93 \%)$ \\
\hline
\end{tabular}

prediagnostic smear was positive for both AAV and HPV DNA while 10 biopsy case samples had both AAV and HPV DNA. None of the matched control smears were positive for both viruses. Ninety-seven samples were both negative for HPV and AAV-2 (Table 3).

\section{DISCUSSION}

Adeno-associated virus-2 is considered a common infection worldwide in both adults and children with seroprevalence from 30 to $60 \%$ according to a study done involving individuals from Germany, Brazil and Japan (Erles et al, 1999). Furthermore, AAV has been postulated to be sexually transmitted as AAV DNA had been isolated from cervical samples, semen, spontaneously aborted material and gestational human trophoblasts (Atchison et al, 1965; Tobiasch et al, 1994; Kiehl et al, 2002).

It was suggested from previous seroepidemiological studies that AAV infection could protect women against the development of cervical cancer (Mayor et al, 1976). However, there were other studies that showed no significant difference between the seroprevalence for AAV among cases and controls, although lower antibody titers among cancer patients than among non-cancer patients were seen (Georg-Fries et al, 1984; Strickler et al, 1999; Smith et al, 2001).

DNA-based analysis on clinical samples taken from the cervix has reported inconsistent results regarding AAV and cervix cancer. Some studies detected high prevalence AAV-2 DNA in cervical samples (Han et al, 1996; Ahn et al, 2003). However, others found that AAV prevalence was not high in cervical tissue (Grossman et al, 1992; Strickler et al, 1999; Odunsi et al, 2000). Based on our optimised and sensitive PCR systems, a low proportion of samples were found positive are well in line with the reports of absence or low prevalence of AAV, irrespective of the nature of the samples (Grossman et al, 1992; Odunsi et al, 2000).

Experimentally, in-vitro co-infection of AAV and HPV may involve complex molecular/biological interactions that result in either the repression or promotion of HPV replication. In-vitro experiments using organotypic 'raft' culture system, which enable epithelial cells to reach terminal differentiation and thereby support the complete HPV life cycle indicated that when AAV-2 was present at low multiplicity of infection (MOI), HPV replication was slightly increased. The reverse was seen at high AAV MOI. Thus, suggesting that AAV may have a significant effect upon the kinetics of HPV life cycle regulation in the natural host tissue, where the exact mechanism behind the interaction effect is still largely unknown (Meyers et al, 2001; Agrawal et al, 2002).

Our study base is a population-based cohort of healthy women who did or did not develop cervical cancer on follow-up. It is a reliable study design to evaluate possible risk factors. The study design using closed cohorts with comprehensive case assessment actually has minimal risks for selection biases. All Pap smears analysed in our study were cytological normal, and the baseline for AAV DNA prevalence among case-women was low (2\%), as compared to $3 \%$ among control-women. The low prevalence in our study material could be influenced by the nature of the specimen. Fixed and stained samples often present with degradation of DNA. To overcome any technical problem, the PCR systems used had been carefully optimised, validated with variable template volumes used to overcome the effect of inhibition. Furthermore, the PCR products produced were within the range suitable for amplification by PCR from archival DNA. However, biopsies contain more cells as compared to smears and that could have contributed to greater success in amplifying AAV DNA. The detection limits for the PCR systems we used were similar for both biopsy and Pap smear. Despite the higher AAV DNA prevalence among the invasive cancers $(11 \%)$ as compared to the matched smears from controlwomen, the data suggest an association but a larger sample population utilizing fresh smears or biopsies should be ideal.

In conclusion, we found a low proportion of cervical cancer biopsies contain AAV-2 genomes. In addition, AAV DNA persistence was not detectable in our longitudinal study. Adenoassociated virus- 2 infection cannot be associated with decreased or increased risk for future development of cervical cancer.

\section{ACKNOWLEDGEMENTS}

We thank Anita Schorlemmer for the careful optimisation of the PCR analyses, and the project has been supported by the Swedish Cancer Society, Stockholm County Council, the Swedish Medical Research Council and Swedish Cancer Foundation.

\section{REFERENCES}

Agrawal N, Mane M, Chiriva-Internati M, Roman JJ, Hermonat PL (2002) Temporal acceleration of the human papillomavirus life cycle by adenoassociated virus (AAV) type 2 superinfection in natural host tissue. Virology 297: $203-210$

Ahn WS, Bae SM, Chung JE, Lee HK, Kim BK, Lee JM, Namkoong SE, Kim CK, Sin J (2003) Evaluation of adenoassociated virus 2 and human papilloma virus 16 and 18 infection in cervical cancer biopsies. Gynecol Oncol 89: $105-111$

Ahn WS, Bae SM, Lee HJ, Kim YW, Lee JM, Namkoong SE, Kim CK, Jin HS (2006) Development of anticancer gene vaccine interact with human papillomavirus oncoprotein inhibition. Int J Gynecol Cancer 16: 270-276

Alazawi W, Pett M, Arch B, Scott L, Freeman T, Stanley MA, Coleman N (2002) Changes in cervical keratinocyte gene expression associated with integration of human papillomavirus 16. Cancer Res 62: 6959-6965

Atchison RW, Casto BC, Hammon WM (1965) Adenovirus-associated defective virus particles. Science 149: $754-756$

Buller RM, Janik JE, Sebring ED, Rose JA (1981) Herpes simplex virus types 1 and 2 completely help adenovirus-associated virus replication. $J$ Virol 40: $241-247$

Chua KL, Wiklund F, Lenner P, Angstrom T, Hallmans G, Bergman F, Sapp M, Schiller J, Wadell G, Hjerpe A, Dillner J (1996) A prospective study on the risk of cervical intra-epithelial neoplasia among healthy subjects with 
serum antibodies to HPV compared with HPV DNA in cervical smears. Int J Cancer 68: $54-59$

Coker AL, Russell RB, Bond SM, Pirisi L, Liu Y, Mane M, Kokorina N, Gerasimova T, Hermonat PL (2001) Adeno-associated virus is associated with a lower risk of high-grade cervical neoplasia. Exp Mol Pathol 70: $83-89$

Erles K, Sebokova P, Schlehofer JR (1999) Update on the prevalence of serum antibodies (IgG and IgM) to adeno-associated virus (AAV). J Med Virol 59: 406-411

Evander M, Boden E, Bjersing L, Rylander E, Wadell G (1991) Oligonucleotide primers for DNA amplification of the early regions 1 , 6, and 7 from human papillomavirus types 6, 11, 16, 18, 31, and 33. Arch Virol 116: $221-233$

Friedman-Einat M, Grossman Z, Mileguir F, Smetana Z, Ashkenazi M, Barkai G, Varsano N, Glick E, Mendelson E (1997) Detection of adenoassociated virus type 2 sequences in the human genital tract. J Clin Microbiol 35: $71-78$

Georg-Fries B, Biederlack S, Wolf J, zur Hausen H (1984) Analysis of proteins, helper dependence, and seroepidemiology of a new human parvovirus. Virology 134: $64-71$

Ghaderi M, Wallin KL, Wiklund F, Zake LN, Hallmans G, Lenner P, Dillner J, Sanjeevi CB (2002) Risk of invasive cervical cancer associated with polymorphic HLA DR/DQ haplotypes. Int J Cancer 100: 698-701

Grossman Z, Mendelson E, Brok-Simoni F, Mileguir F, Leitner Y, Rechavi G, Ramot B (1992) Detection of adeno-associated virus type 2 in human peripheral blood cells. J Gen Virol 73(Part 4): 961-966

Han L, Parmley TH, Keith S, Kozlowski KJ, Smith LJ, Hermonat PL (1996) High prevalence of adeno-associated virus (AAV) type 2 rep DNA in cervical materials: AAV may be sexually transmitted. Virus Genes 12: $47-52$

Henry CJ (1973) Adenovirus-associated (satellite) viruses. Prog Exp Tumor Res 18: $273-293$

Hermonat PL (1994) Adeno-associated virus inhibits human papillomavirus type 16: a viral interaction implicated in cervical cancer. Cancer Res 54: $2278-2281$

Hermonat PL, Plott RT, Santin AD, Parham GP, Flick JT (1997) Adenoassociated virus Rep78 inhibits oncogenic transformation of primary human keratinocytes by a human papillomavirus type 16-ras chimeric. Gynecol Oncol 66: 487-494

Kiehl K, Schlehofer JR, Schultz R, Zugaib M, Armbruster-Moraes E (2002) Adeno-associated virus DNA in human gestational trophoblastic disease. Placenta 23: $410-415$

Koskela P, Anttila T, Bjorge T, Brunsvig A, Dillner J, Hakama M, Hakulinen T, Jellum E, Lehtinen M, Lenner P, Luostarinen T, Pukkala E, Saikku P, Thoresen S, Youngman L, Paavonen J (2000) Chlamydia trachomatis infection as a risk factor for invasive cervical cancer. Int J Cancer 85: $35-39$

Mayor HD, Drake S, Stahmann J, Mumford DM (1976) Antibodies to adeno-associated satellite virus and herpes simplex in sera from cancer patients and normal adults. Am J Obstet Gynecol 126: $100-104$

Mehrle S, Rohde V, Schlehofer JR (2004) Evidence of chromosomal integration of AAV DNA in human testis tissue. Virus Genes 28: $61-69$
Meyers C, Alam S, Mane M, Hermonat PL (2001) Altered biology of adenoassociated virus type 2 and human papillomavirus during dual infection of natural host tissue. Virology 287: 30-39

Munoz N, Bosch FX, de Sanjose S, Herrero R, Castellsague X, Shah KV, Snijders PJ, Meijer CJ (2003) Epidemiologic classification of human papillomavirus types associated with cervical cancer. $N$ Engl J Med 348: $518-527$

Odunsi KO, van Ee CC, Ganesan TS, Shelling AN (2000) Evaluation of the possible protective role of adeno-associated virus type 2 infection in HPV-associated premalignant disease of the cervix. Gynecol Oncol 78: $342-345$

Salo RJ, Mayor HD (1979) Adenovirus-associated virus polypeptides synthesized in cells coinfected with either adenovirus or herpesvirus. Virology 93: 237-245

Schiffman MH, Castle P (2003) Epidemiologic studies of a necessary causal risk factor: human papillomavirus infection and cervical neoplasia. J Natl Cancer Inst 95: E2

Schlehofer JR, Ehrbar M, zur Hausen H (1986) Vaccinia virus, herpes simplex virus, and carcinogens induce DNA amplification in a human cell line and support replication of a helpervirus dependent parvovirus. Virology 152: 110 - 117

Smith J, Herrero R, Erles K, Grimm D, Munoz N, Bosch FX, Tafur L, Shah KV, Schlehofer JR (2001) Adeno-associated virus seropositivity and HPV-induced cervical cancer in Spain and Colombia. Int J Cancer 94: $520-526$

Strickler HD, Viscidi R, Escoffery C, Rattray C, Kotloff KL, Goldberg J, Manns A, Rabkin C, Daniel R, Hanchard B, Brown C, Hutchinson M, Zanizer D, Palefsky J, Burk RD, Cranston B, Clayman B, Shah KV (1999) Adeno-associated virus and development of cervical neoplasia. J Med Virol 59: $60-65$

Su PF, Wu FY (1996) Differential suppression of the tumorigenicity of HeLa and $\mathrm{SiHa}$ cells by adeno-associated virus. Br J Cancer 73: 1533-1537

Tobiasch E, Burguete T, Klein-Bauernschmitt P, Heilbronn R, Schlehofer JR (1998) Discrimination between different types of human adenoassociated viruses in clinical samples by PCR. J Virol Methods 71: 17-25

Tobiasch E, Rabreau M, Geletneky K, Larue-Charlus S, Severin F, Becker N, Schlehofer JR (1994) Detection of adeno-associated virus DNA in human genital tissue and in material from spontaneous abortion. J Med Virol 44: $215-222$

Venturoli S, Cricca M, Bonvicini F, Gallinella G, Gentilomi G, Zerbini M, Musiani M (2001) Detection of adeno-associated virus DNA in female genital samples by PCR-ELISA. J Med Virol 64: 577-582

Wallin KL, Wiklund F, Angstrom T, Bergman F, Stendahl U, Wadell G, Hallmans G, Dillner J (1999) Type-specific persistence of human papillomavirus DNA before the development of invasive cervical cancer. $N$ Engl J Med 341: 1633 - 1638

Walz C, Schlehofer JR (1992) Modification of some biological properties of $\mathrm{HeLa}$ cells containing adeno-associated virus DNA integrated into chromosome 17. J Virol 66: 2990-3002

Zhan D, Santin AD, Liu Y, Parham GP, Li C, Meyers C, Hermonat PL (1999) Binding of the human papillomavirus type $16 \mathrm{p} 97$ promoter by the adeno-associated virus Rep78 major regulatory protein correlates with inhibition. J Biol Chem 274: 31619-31624 